POLLACK PERIODICA

An International Journal for Engineering and Information Sciences

DOI: $10.1556 / 606.2016 .11 .2 .7$

Vol. 11, No. 2, pp. 75-86 (2016)

www.akademiai.com

\title{
MULTI CRITERIA OPTION ANALYSIS IN THE TECHNOLOGY DESIGN OF MECHANICAL- BIOLOGICAL TREATMENT OF WASTE
}

\author{
Csaba LEITOL \\ Department of Environmental Engineering, Faculty of Engineering and Information \\ Technology, University of Pécs, Boszokány u. 2, H-7624 Pécs, Hungary \\ e-mail: lcsaba@mkmconsulting.hu
}

Received 31 December 2015; accepted 9 February 2016

\begin{abstract}
The residual waste has a high concentration of recoverable elements, which can be either recycled or recovered into energy in accordance with the waste hierarchy. One option is the implementation of mechanical biological treatment of waste, which has showed a steady progress in the recent two years in Hungary.

This paper analysis the relevant factors, which should be considered during the technology planning. The multi criteria analysis involves the economical environmental and external considerations into the technology assessment. Based on the results, the technology plan should be revised and adjusted.
\end{abstract}

Keywords: Mechanical and biological treatment, Waste treatment, Energy recovery, Refuse derived fuel, Solid recovered fuel, Market requirements, Efficiency, Life-cycle analysis, Multi loop based multi criteria analysis

\section{Introduction}

In accordance with the Waste Framework Directive (2008/98/EC) [1] the waste hierarchy shall apply as a priority order in the integrated waste management systems where beside the implementation of prevention and prevention for reuse measures, recycling and other recovery activates should be prioritized, and disposal, as landfilling should only be used as a final option. Further to this, 1999/31/EC [2] prescribes strict technological and environmental criteria for all waste disposal activities, requiring EU Member States for setting up national strategies for the implementation of the reduction 
of biodegradable waste going to landfills and to ensure that only waste that has been subject to treatment is landfilled.

Further to this the new EU policy on waste (COM (2015) 614/2) [3] states, that funding for new facilities for the mechanical biological treatment of residual waste will be granted only in limited and well justified cases, where there is no risk of overcapacity and the objectives of the waste hierarchy are fully respected.

Selective collection of waste is a requirement for proper recycling of certain fractions of waste, but non-selectively collected residual waste also has further recycling and recovery options. The Mechanical and Biological Treatment of waste (MBT) enables the automation of the separation of homogeneous waste fractions suitable for further recycling or energy recovery. The biological treatment technology aims to eliminate the biodegradable fraction from the landfilled waste, also reducing the volume of waste to be disposed.

The amount of residual waste treated for producing combustible waste fractions for further incineration has showed a steady increase in the member states of the EU. In accordance with the research of Ecoporg, the following trends can be observed: the number MBT facilities have reached 330 till 2011, and their input capacity exceeded 33 million tons of waste. This progress will continue further, by 2015 the estimated capacity will be 46 million tons of the 460 facilities [4].

Presently the largest MBT capacity has been built in Italy, where 14 million tons of waste is treated in 133 facilities [5]. In Germany, which has the longest tradition of MBT treatment, the existing 61 facility has a capacity of 6.4 million tons per year [6].

In Hungary 19 MBT facilities were in operation, able to produce Refuse Derived Fuel (RDF), or Solid Recovered Fuel (SRF) with an input capacity of 910 thousand tons per year. The first MBT was built in 2005, but significant progress has been made during the years of 2014 and 2015 , when $83.5 \%$ of all the presently available capacity (i.e. 760 thousand tons per year) was established. Five further facilities are under construction, with an overall capacity of 220 thousand tons per year, resulting that by the end of 2016 the total capacity will reach the 1.1 million tons per year threshold, which is equal to $2.5 \%$ of all the MBT capacity of Europe. Despite this theoretical input capacity, the amount of treated waste was 50 thousand tons in 2013 and 91 thousand tons in 2014.

The technology advance level of implemented MBTs shows a huge variety. This is reflected in the quality of equipment and their technological parameters, the flexibility of the technology, and the sequence of technology elements, together with the methods of transporting material, the efficiency of the sorting machinery and their parameters installed, combined with different system management solutions.

\section{Methodology}

\subsection{Composition of waste and its parameters}

During the technology planning, the amount of input waste is a basic parameter. A future prognosis should be made based on the alterations in the amount of input 
material, with respect to the actual waste treatment trends e.g. how, and to which amount the input waste changes compared to the data of the previous years.

The expected changes in the waste management system itself, is also significantly influences the amount of input material of MBTs. These changes may include the introduction of selective collection of recyclables, or the enlargement of the existing schemes, together with the selective collection of garden or biodegradable waste. Introducing a selective collection system - after some years of its operation - may decrease the input material supply of an MBT up to 30\% [7].

Beside the amount of waste, the composition is also a basic parameter. In order to support adequate planning the composition should be studied both on seasonal and on urban area type bases, including separate analysis for cities (block-of-flat areas, inner town, residential areas) and urban settlements. Summarizing the seasonal data on yearly bases balanced with the size of the different urban area types the average composition can be calculated for the whole collection district. The Hungarian national regulations also prescribe that the composition analysis should be in accordance with the sampling and sample analysis patterns of MSZ 21420-28 and 29 [8], [9].

Apart from the general waste composition the exact composition of the different grain size fraction is also an important factor. In order to gain this data, the samples of residual waste, should be sized by an array of different sieves (having $10 \mathrm{~mm}$ size difference in a descending order), in order to determine the waste composition of the different size ranges. This provides the necessary information for the optimal technology parameters of size ranges.

In order to determine the annual changes in waste generation, data of succeeding years should also be compared.

\subsection{Analysis of the technology}

The sequence of technology elements can be influenced by several factors in connection with the requirements for the quality of the output fuel material. It may require extra machinery (e.g. optical separators in case of chloride content) to reduces certain contaminations in the waste stream. The fuel granule size also influences the efficiency of secondary-shredders; the smaller the granule is the more secondaryshredder capacity is required. The requirements of the further processing plant will determine the manner and the extent of the output material treatment.

During the analysis three MBTs - having identical technology - have been compared based on

1) the composition of input waste;

2) the optimal separation point for sizing;

3) the composition of the output waste; and

4) the parameters of the fuel material.

The applied technology processes are as follows:

- pre-selection (removing interfering substances and material containing PVC);

- pre-shredding (300-350 mm, homogenization);

- separation of ferrous material I;

- sifting (separation of fractions with high biodegradable content, $60-80 \mathrm{~mm}$ ); 
- separation of non-ferrous material (aluminum, copper);

- isolation of heavy material (air separation);

- secondary-shredding (granule size for material recovery $50 \mathrm{~mm}$ );

- separation of ferrous material II;

- preparing for further transport.

\section{Results and discussion}

\subsection{The parameters of input waste}

The MBT is a technology for the treatment of residual municipal waste. It is essential to have knowledge over the main parameters of local waste characteristics, to select suitable technology equipment. The generated municipal waste is influenced by the living standards, consumer habits, settlement structure, the local culture and seasonal influences.

The analysis of the waste composition was done at the Pécs-Kökény MBT establishment. The results are presented in Table I.

Table I

Waste composition

\begin{tabular}{|c|c|c|c|c|c|}
\hline \multirow[t]{2}{*}{ Classification } & \multicolumn{5}{|c|}{$2014(\%)$} \\
\hline & 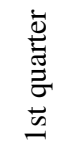 & 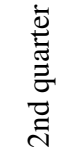 & 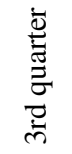 & 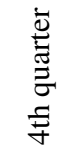 & 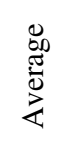 \\
\hline Biodegradable & 20.3 & 20.7 & 29.6 & 27.6 & 24.5 \\
\hline Paper & 14.7 & 13.2 & 8.5 & 11.4 & 12.0 \\
\hline Cardboard & 7.0 & 5.1 & 3.8 & 5.0 & 5.2 \\
\hline Mixed packaging & 7.1 & 5.2 & 2.2 & 2.8 & 4.3 \\
\hline Textile & 5.4 & 4.3 & 6.8 & 4.1 & 5.2 \\
\hline Hygiene waste & 4.4 & 4.0 & 4.2 & 5.6 & 4.5 \\
\hline Plastic & 16.3 & 16.6 & 18.9 & 19.9 & 17.9 \\
\hline $\begin{array}{l}\text { Non-classified } \\
\text { combustible waste }\end{array}$ & 4.8 & 4.5 & 6.6 & 4.6 & 5.1 \\
\hline Glass & 4.2 & 4.3 & 2.1 & 4.4 & 3.8 \\
\hline Metal & 3.3 & 3.9 & 3.7 & 2.2 & 3.3 \\
\hline $\begin{array}{l}\text { Non-classified non- } \\
\text { combustible waste }\end{array}$ & 4.1 & 6.4 & 6.3 & 3.1 & 5.0 \\
\hline Hazardous waste & 0.8 & 0.5 & 0.6 & 1.0 & 0.7 \\
\hline Small granule waste & 7.7 & 11.3 & 6.8 & 8.4 & 8.5 \\
\hline Total: & 100 & 100 & 100 & 100 & 100 \\
\hline
\end{tabular}

The composition of the input municipal waste material of MBT is further determined by the status of selective collection, including its extent, type and maturity. The more

Pollack Periodica 11, 2016, 2 
advanced the selective collection system is the less combustible components (i.e. plastic, paper, textile, wood) remains in the residual waste contributing also to a reduction of calorific value of RDF [10]. On the contrary, the selective garden and biodegradable waste collection - by reducing the humid content of waste - contributes to better combustibility.

It is difficult to prepare an adequate prediction for the change in the waste composition, since certain elements may show hectic alterations. Some of the elements are correlated with external environmental factors (e.g. seasonality). This is well illustrated by the examples of

a) increased volume of garden waste in the $3^{\text {rd }}$ and $4^{\text {th }}$ quarter, increasing the amount of biodegradable waste in the composition;

b) increased volume of plastics (i.e. PET bottles) in the summer period as result of increased consumption of mineral water.

The seasonal changes in the Pécs-Kökény collection district during the period of 2011-2014 are illustrated by Fig. 1 in monthly breakdown. It can be well conceived that the amount of waste is at its minimal at the beginning and at the end of the year, and the peak season is July-September.

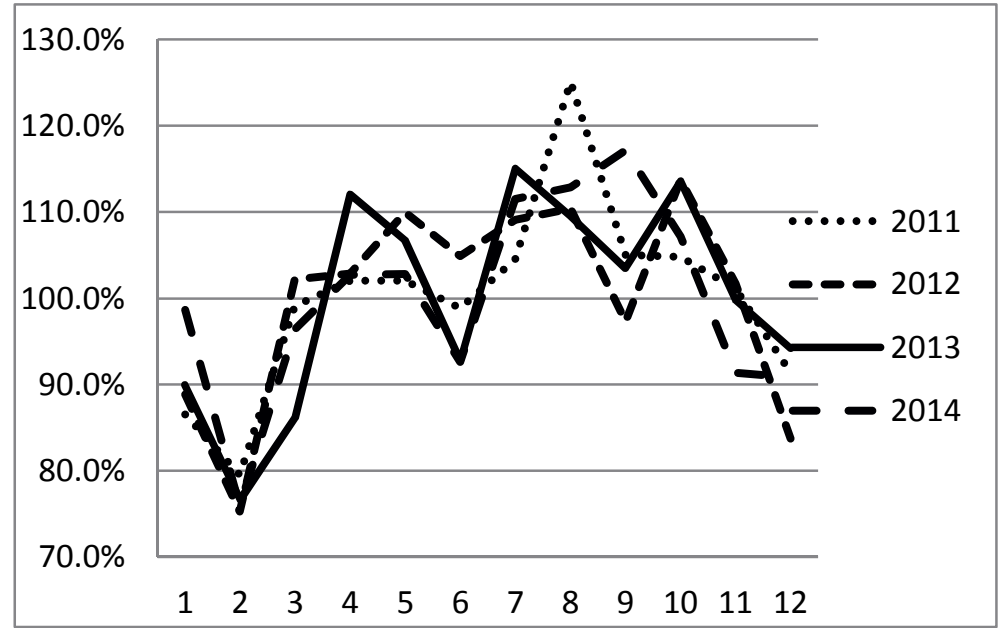

Fig. 1. Seasonal changes of waste volume on monthly breakdown, compared to yearly average

To plan the processing technology, the waste distribution based on grain size is a crucial factor. The grain size influences the efficiency of the mechanical processing and the applicability of certain separation technology.

As it is illustrated in Fig. 2, the granule distribution of the waste from the PécsKökény collection district shows similar characteristics when compared with the data from the research conducted at Hejöpapi [11]. 


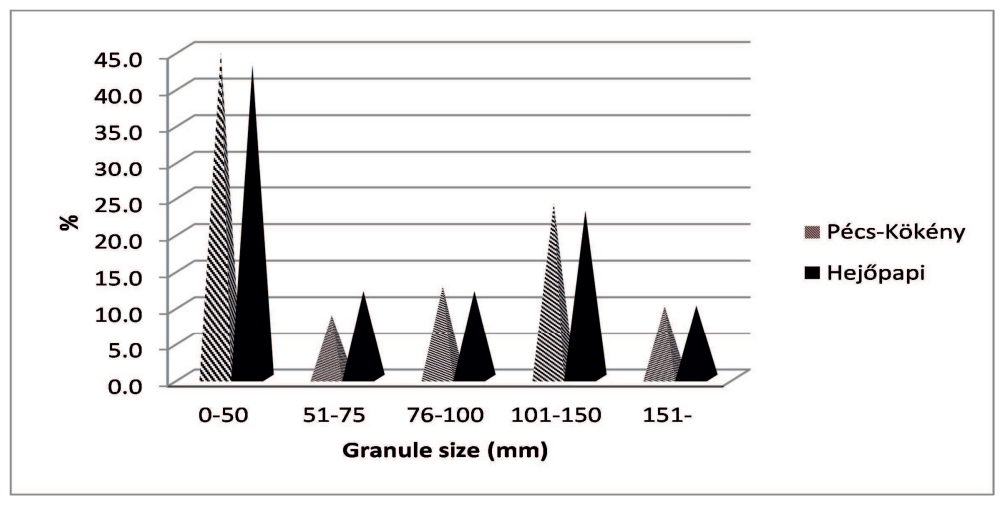

Fig. 2. Distribution of grain sizes

Within the different grain size ranges the composition of the waste is different, which is also affecting the efficiency of applicable technology processes [12]. Each waste component has its grain size limit, which separates the majority of this kind of waste component, sorting it into either the lower, or upper size fractions. Other research results showed that pairing the suitable composition to the suitable granule size can be the bases of technology planning. With a conclusion that more than $80 \%$ of the best combustible fractions (i.e. paper, plastic, textile) are in the upper fraction of the $50 \mathrm{~mm}$ size, while $90 \%$ of biodegradable waste is in the lower fraction of the $75 \mathrm{~mm}$ size [13].

Further to this, its volume and composition is also dependent upon seasonal changes.

The distribution in accordance with granule size should be taken into consideration during planning the separation process. This results in selecting the suitable separation size - with regards to the local characteristics of waste - where the majority of the biodegradable waste, which is not suitable for further combustion, can be optimally separated from the rest of the waste flow.

To determine the optimum point of separation, it has to be considered that highest volume of waste fraction aimed to be separated should be in the separated fraction, while the volume of useful material should be minimized in this separated fraction. The separation point is also influenced by the other characteristics of waste (e.g. the sticking and contamination nature of high humidity material) [14].

Comparing the data of three technologically identical systems, having different separation points and input material flows, significant differences can be found in the quality of the output material.

At two MBTs (Pécs-Kökény MBT1, Hejöpapi MBT2) the point of separation is $60 \mathrm{~mm}$ at the third observed MBT (Királyszentistván MBT3) this is $80 \mathrm{~mm}$. Selective collection of garden waste is carried out at both places, but the availability rate is $100 \%$ at MBT2 and only $30 \%$ in the case of the other two MBTs. Based on this, at MBT1 and MBT3 the biodegradable fraction in the composition of the input material is almost identical, more than $20 \%$, resulting that the waste humidity is higher and in most of the cases it exceeds $30 \%$.

As it is presented in Table II, the major difference is in the biodegradable and the RDF fractions. The highest biodegradable fraction is at MBT2, which partly derives 
from the highest $(80 \mathrm{~mm})$ point of separation, and the higher biodegradable fraction of the input waste compared to MBT3. In opposition to the case of the biodegradable fraction, the RDF output highest in MBT1 (36.35\%).

Table II

The output of certain technologies

\begin{tabular}{|l|r|r|r|}
\hline & MBT1 & MBT2 & MBT3 \\
\hline Point of separation (mm) & 60 & 60 & 80 \\
\hline Biodegradable (\%) & 55.28 & 63.81 & 72.93 \\
\hline RDF (\%) & 36.35 & 21.64 & 15.98 \\
\hline Metal (\%) & 2.05 & 1.46 & 0.34 \\
\hline Heavy fraction (\%) & 5.25 & 8.49 & 9.87 \\
\hline Other (\%) & 1.07 & 4.6 & 0.88 \\
\hline
\end{tabular}

More significant differences can be detected, when the calorific values are compared base on the humid material content based on the as received (ar) material.

The highest figure of MBT2 is more than $16 \mathrm{MJ} / \mathrm{kg}$, which is in close relation to the below $15 \%$ humidity content of the input material. The difference between MBT1 and MBT3 is a result of the different point of separation [15], [16], [17].

Examining the outputs in Table II it can be concluded that in the case of MBT3 the biodegradable fraction is $72.93 \%$, compared to the $55-63 \%$ value of the other two MBTs, which results in higher volume separation of humid and contaminated waste fraction. This will result in reducing the volume of the RDF fraction, but at the same time it improves its calorific value.

The output RDF fractions are further analyzed based on their combustibility as presented in Fig. 3. According to these findings, it can be concluded that that there is only a slight difference in calorific values of output material, if it is calculated based on the dry (d) material content.

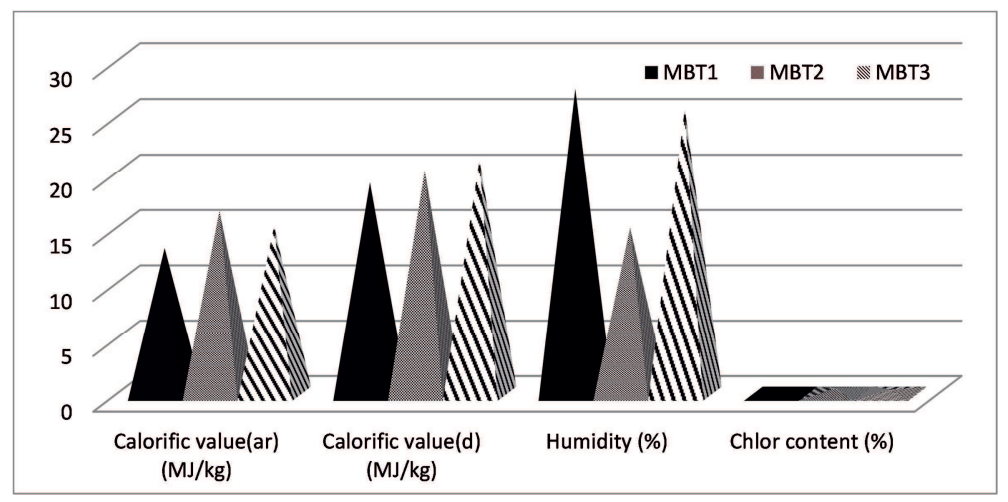

Fig. 3. RDF characteristics 
According to these findings, it can be concluded that there is only a slight difference in calorific values of output material, if it is calculated based on the dry (d) material content.

During the planning of MBT technology - besides defining the quantity and quality of input material - it is also a crucial factor to map the requirements for the further treatment options of the output fractions. With regard to this, the main outputs of MBTs, can be used in energy recovery schemes (i.e. in case of RDF/SRF) can be recycled (i.e. in case of ferrous metals, aluminum, copper or certain plastics) and bio-stabilized waste (Compost Like Output (CLO)).

The technology sequence of MBT equipment (i.e. shape, size, specific weight separation device, etc.) regarding their number, sequence and the necessity for additional machinery necessary for conducting further treatment steps are depending upon the requirements for the further treatment of the output material.

Different output requirements are set for fuel material supplied to cement factories, power plants or waste incineration plants. The strictest requirements are prescribed at the co-incineration schemes of cement factories, where input material is screened for calorific value, chloride, halogen, mercury and other metal content, together with requiring the elimination of all interfering substances, which may negatively influence the clinker production process. Beside the quality of the fuel material, the suitable granule size is also influenced by the requirements of the feeding device of the combustion area; together with the logistic needs of a continuous supply (i.e. bulk or bailed material is more practical for further processing) [18].

The bio-stabilized waste has also further treatment options. The simplest ones are the incineration, or co-incineration in power plant, which do not require any further technology steps. In case of supplying this material to a higher requirement cement factory or co-incineration power plant, further treatment is necessary to separate the higher calorific value fraction from the interfering and soil like composted substances. This option should have been already taken into account during the planning of the technology sequence, in order to make it possible to feed in this kind material to the processing lines, at a suitable location.

Establishing separate locations for feed in and collecting the output material at certain points of the technology line is a necessity to make the flexible adaptation of MBT possible in relation to the changing market needs. If intermediate feeding options are available within the technology line, input material can avoid shredding (if it is not necessary), or combustible material from the biodegradable output can be fed back to the line, since this kind of material may also require further pre-treatment steps (i.e. separation of ferrous metal. aluminum. copper or heavy material etc.).

Apart from flexible feeding, it is also important, that the output material can be taken out at certain points of the line, even if it is only half-processed, in line with the actual market requirements for the quantity of quality of the output.

The third requirement of flexibility is to build out a technology for the optional separation of recyclables (e.g. plastics). One possibility is the near infrared separating technology, which can be programmed to separate PVC, - which is crucial to be separated do to its problematic nature during incineration - and other plastic material from the main waste flow. 
In order to ensure that the implemented technology can be operated efficiently beside the requirements of the best available technology - the selection process also has to take into account the local economic, social and environmental aspects. The possible technology options for the MBT should also be evaluated against these aspects. As far as these processes are overlapping, only a complex evaluation methodology can lead to an optimum selection.

Regarding the environmental aspects, the best option for an adequate analysis in a measurable and replicable way is using the Life Cycle Analysis (LCA) methodology. During the LCA the evaluation involves both the environmental factors, the operational efficiency (output volumes), and the marketability of outputs is [19]. On the environmental benefit side, it is also acknowledged adequately, that using RDF in energy production can substitute primary energy sources [20].

The LCA findings enable to suggest technology improvements based on environmental performance factors, and the monetized environmental costs and benefits of the LCA can be a valuable input for the calculation of the Cost Benefit Analysis (CBA). The LCA results enable the selection of the technology option most preferable from an environmental point of view [21].

Extending the LCA framework with further analysis of financial factors (i.e. investment, operation cost, incomes. fees and subsidies, etc.) the best value for money option can be selected by addressing both the environmental and financial factors. Taking into account the issues of market uncertainties, the calculations can also be extended with sustainability, sensibility and risk analysis and coupled with an environmental analysis (calculation of external cost. benefits) based on the results of LCA [22].

If the final results of the CBA is based on a complex LCA, the planner may get a direct feedback from this analysis, on how the technology can be further improved by modifying the original technology plans, which will also modify the results of LCA and the CBA and a new technology improvement loop begins. until the optimum solution is reached.

This planning process is the multi loop based multi criteria analysis, which consists of the following elements:

- Local conditions analysis;

○ Local enabling framework;

- Features of the input material;

- Market analysis;

○ Output requirements;

- Market changes;

- Financial and environmental cost and income analysis of options;

- Evaluation of the environmental aspects;

○ Life-Cycle Thinking / Life-Cycle Assessment (LCT/LCA);

- Feedback (starting a new loop if proves necessary).

The multi loop based multi criteria analysis is presented in Fig. 4. 


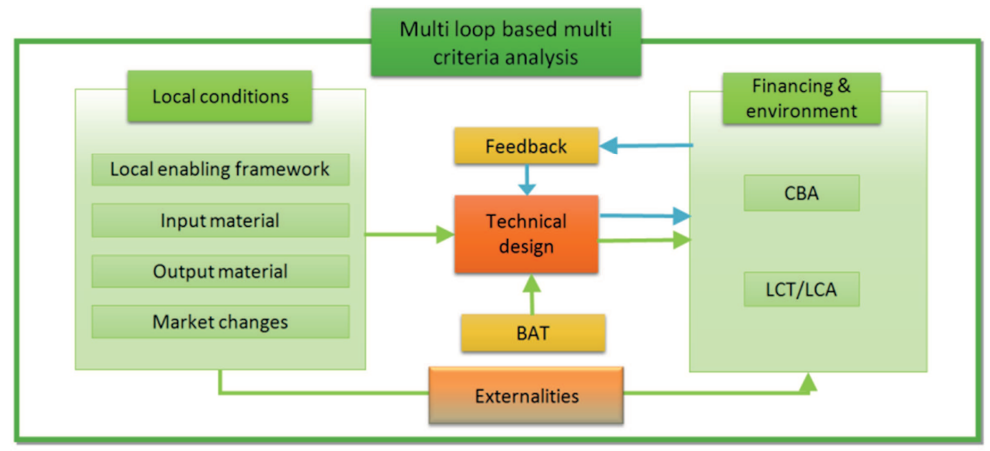

Fig. 4. The multi loop based multi criteria analysis

\section{Conclusions}

Based on these findings, it can be declared that the residual municipal waste cannot be handled as a classic raw material, due to its inhomogeneous nature both regarding its physical, chemical and biological characteristics.

It can be concluded - that beside the composition of the input material - the volume and the quality (i.e. composition, content of interfering substances, humidity etc.) of the output material is also influenced by how the point of separation is selected. Further to this, feeding to the same technology (having identical point of separation) with different composition of input material (i.e. different biodegradable content, humidity) results in different volume and quality (i.e. different calorific value) at the output side.

The technology planning phase of MBT plants should involve a complex multi criteria option analysis, focusing on both evaluating the best available technologies and the optimal separation of material flows aiming to maximize the quality and the quantity of the fractions suitable for recycling or energy recovery. The technology can be further refined by applying a multi loop based improvement process based on LCA and CBA results.

The criteria to be involved in the technology option analysis are:

- Determining the elements of the local enabling framework (waste volumes, logistics, options for further recycling or recovery, local economic and legal conditions);

- The quality and quantity of the input material, waste composition, physicalchemical-biological characteristics, together with the modeling of future trends both regarding the expected change in the composition and the quantity;

- Input requirements of the external local options, for further recycling or recovery of the processed outputs of MBT plants. This results in setting requirement parameters for MBT outputs regarding caloric value, composition, size of granules, humidity, homogeneity, quantity;

- Ensuring the flexible technology adaptation for market requirement changes, both at the input and output side of the MBT plants, by implementing automated 
flexible solutions with multiple options for material input and output at different stages of the waste treatment process;

- To select the options that delivers the best overall environmental performance, specific waste streams departing from the waste hierarchy within the MBT should be justified by life-cycle thinking on the overall impacts of the generation and management of such waste.

Resource efficient technology planning of MBT plants can only be ensured, if the above described multi criteria technology option analysis is involved into the technology feasibility analysis of the whole investment, results are looped back to the technology planning phase to provide information for the planner on the required changes to reach full efficiency.

Further to that this approach ensures the implementation of a technology, which corresponds with the local enabling framework, but also supplies optimal output together with enabling the adjustments in the RDF/SRF quality parameters of the output material. This flexibility requirement of the technology is inevitable to ensure the long term sustainability and affordability of the future operation of the plant, enabling the operator the possibility to adapt to external market requirements - influenced by the altering input material demand - by producing a supply of different quantity and quality of waste fraction outputs, suitable for further recycling or energy recovery.

\section{Acknowledgements}

This work has been undertaken as a part of a project founded by the Department of Environmental Engineering, Faculty of Engineering and Information Technology, University of Pécs. Special thanks to the employees of BIOKOM Nonprofit Ltd, who supported this research with their work.

\section{References}

[1] Directive 2008/98/EC of the European Parliament and of the Council of 19 November 2008 on waste and repealing certain directives, Official Journal, L 312, 22 November 2008, pp. 0003-0030.

[2] Council Directive 1999/31/EC of 26 April 1999 on the landfill of waste, Official Journal L 182, 16 July 1999, pp. 0001-0019.

[3] European Comission, Closing the loop - An EU action plan for the circular economy, $\operatorname{COM}(2015)$ 614/2, http://ec.europa.eu/priorities/jobs-growth-investment/circular-economy/ docs/communication-action-plan-for-circular-economy_en.pdf, (last visited 30 December 2015).

[4] Ecoprog, Study the European market for MBT plants 2011/2012, http://www.ecoprog. com/en/publications/waste-industry/mbt.htm (last visited 30 December 2015).

[5] Nelles M., Morscheck G., Grünes J., MBT in Germany and Europe, development, status and outlook, International 9th ASA Recycling Days MBT as a Supplier of Secondary Raw Materials, Hanover, Germany 29 February - 2 March 2012, pp. 1-16.

[6] Thiel S., Thomé-Kozmiensky J. K. Mechanical-biological pretreatment of waste, Hope and reality, In: Papers and Proceedings of the ISWA World Congress 2010, Urban 
Development and Sustainability, a Major Challenge for Waste Management in the 21th Century, Hamburg, Germany, 15-18 November 2010, pp 1-16.

[7] Leitol Cs. Resource efficiency of Hungarian recycling systems, Pollack Periodica, Vol. 7, No. 2, 2012, pp. 117-127.

[8] Hungarian Standards Institution, MSZ 21420-28, Characterization of wastes, Part 28: Investigation of municipal wastes, Sampling, 2005.

[9] Hungarian Standards Institution, MSZ 21420-29, Characterization of wastes, Part 29: Investigation of municipal wastes, Preparation of sample, characterization of material composition by the selection of material categories, 2005.

[10] Calabrò S. P. The effect of separate collection of municipal solid waste on the lower calorific value of the residual waste, Waste Management \& Research, Vol. 28, 2010, pp. 754-758.

[11] Nagy S., Cseppely V. Experimental study of high calorific MBT's products, Hulladék Online, Vol. 3, No. 1, 2012, pp. 1-10, http://folyoirat.hulladekonline.hu/files/189/ (last visited 30 December 2015).

[12] Arina D., Orupe A. Characteristics of mechanically sorted municipal wastes and their suitability for production of refuse derived fuel, Environmental and Climate Technologies, Vol. 8, No. 1. 2012, pp. 18-23.

[13] Kiss T. Economy and system approach in the municipality solid waste management, Ph.D. Thesis, Mikovny Sámuel Doctoral School, University of Miskolc 2007.

[14] Sarkady A., Kurdi R., Rédey Á., RDF, Refuse Derived Fuel, Possibibilities in the NorthBalaton Regional waste management system, Pollack Periodica, Vol. 9, Suppl, 2014, pp. 23-30.

[15] Sarkady A., Kurdi R., Morvai B., Leitol Cs. Diverting municipal solid waste from landfill: new methods in Hungarian waste management, Energy and Sustainability, Special Contributions, Vol. 186, 2015, pp. 303-314.

[16] Ladányi R., Mechanical-optical treatment facility in Hejőpapi, Conference of Köztisztasági Egyesülés, Siófok, Hungary, 21 April 2015, pp. 1-33. http://www.koztegy.hu/ files/ladanyi_roland_1430134415.pdf (last visited 30 December 2015).

[17] Result of Kökény Waste Management Centre 2014, Report of BIOKOM Ltd.

[18] Kiss T., Leitol Cs., Olessák D., Bánhidy J., Szabó L., Drescher L., Víg A,. Nagy Gy., Krasz M., Energy recovery of municipality solid waste, Technical study for Develeopment Direction of Environmental Ministry of Hungary, MKM Consulting Ltd, 2007.

[19] Leitol Cs. Implementing an integrated waste management system in Pécs, Based on lifecycling thinking, 9th International PhD \& DLA Symposium, Pécs, Hungary, 21-22 October 2013, pp. 1-13.

[20] Psomopoulos C. S. Residue derived fuels as an alternative fuel for the Hellenic power generation sector and their potential for emissions reduction, AIMS Energy, Vol. 2, No. 3, 2014, pp. 321-341.

[21] Manfredi S., Pant R. Supporting environmentally sound decisions for waste management A technical guide to Life Cycle Thinking (LCT) and Life Cycle Assessment (LCA) for waste experts and LCA practitioners, European Commission Joint Research Centre, Institute for Environment and Sustainability, Scientific and Technical Reports, 2011.

[22] Kiss T., Leitol Cs., Drescher L., Dolgosné Kovács A., Szűcs I., Vér Cs., Tarkó Z., Comparative analysis of the externalities of Hungarian waste management projects, Régiók Fejlesztése, No. 2. 2013, pp. 103-113. 